Delft University of Technology

\title{
The Assessment of the SCOOT System in Nijmegen
}

Taale, Henk; Middelham, Frans; Dibbits, John; Fransen, Walter

DOI

10.1049/cp:19960292

Publication date

1996

Document Version

Final published version

Published in

Proceedings of the 8th International Conference on Road Traffic Monitoring and Control

\section{Citation (APA)}

Taale, H., Middelham, F., Dibbits, J., \& Fransen, W. (1996). The Assessment of the SCOOT System in Nijmegen. In Proceedings of the 8th International Conference on Road Traffic Monitoring and Control (pp. 66-70). (Conference Publication; No. 422). Institution of Electrical Engineers (IEE).

https://doi.org/10.1049/cp:19960292

Important note

To cite this publication, please use the final published version (if applicable).

Please check the document version above.

\section{Copyright}

Other than for strictly personal use, it is not permitted to download, forward or distribute the text or part of it, without the consent of the author(s) and/or copyright holder(s), unless the work is under an open content license such as Creative Commons.

Takedown policy

Please contact us and provide details if you believe this document breaches copyrights.

We will remove access to the work immediately and investigate your claim. 


\section{THE ASSESSMENT OF THE SCOOT SYSTEM IN NIJMEGEN}

F Middelham and $\mathrm{H}$ Taale

Ministry of Transport, Transport Research Centre

J Dibbits

Municipality of Nijmegen

W Fransen

Witteveen + Bos, Consulting Engineers, The Netherlands

\section{INTRODUCTION}

In a paper for the RTMC-conference in 1994, the feasibility study, the implementation and some experiences with the SCOOT system in the City of Nijmegen in the Netherlands were discussed by Middelham e.a. (1). In this paper the results of the assessment are reported.

The assessment of "SCOOT in Nijmegen" is the final part of a project conducted within the framework of the Second Transport Structure Plan. In 1992 the Transport Research Centre drew up a plan of action by Taale (2) which described how the assessment should be conducted. On the basis of this plan, seven transport consultancies were asked to submit tenders. The contract was awarded to Witteveen+Bos and was completed in December 1994 by Fransen (3).

\section{ASSESSMENT STRUCTURE}

The SCOOT network is given in figure 1. In March, April, May and June 1994 visual and automatic observations were carried out to determine the effects of SCOOT on travel time, delay, flow, speed, queue length, number of stops, gating, bus priority, environment, and management and maintenance. Measurements were made with the existing fixed-time coordinated control system (STAR) for 12 days and with the SCOOT system for 12 days. The measurements were made on Tuesdays and Thursdays from 07.30 to 09.30 hours, 12.00 to 14.00 hours and 16.00 to 18.00 hours. In addition, measurements were made on a limited scale from 21.00 to 23.00 hours.

\section{Identifying disturbances}

The results of the 12 days of measurements were carefully examined to identify disturbances. This was done in 5 stages. In the first stage, attention focused on weather and light conditions. In the subsequent stages, the data were combined and the focus was on outliers, i.e. observations which diverge very markedly from the other data. This may be caused by observational errors or equipment defects. Since the licence number registration method was used, vehicles might be included whose owners stopped en route, e.g. to do some shopping.

\section{Derivation of the other variables}

In reality, only journey times per route and the number of stops were measured. Given the distance, the speed can be calculated from the journey time. The delay was calculated from the 5 percentile from the distribution of journey times at the lower end of the scale. The queue length was derived from the number of directly measured stops. Finally, the environmental effects were determined on the basis of a formula based on route length, delay and the number of stops.

\section{Comparison of traffic density}

A comparison of two control strategies is worthwhile only if the conditions in both are more or less identical. We examined the density at the main inputs to the network, taking into account the effect of any queues. The assumption is (in view of the selected regime: one week SCOOT, one week STAR, etc.) that the control strategy does not affect the network load. It was demonstrated that the measurements for all the periods studied could be compared.

\section{Statistical tests used}

In all cases, the analyses were based on a statistical test of a hypothesis. A total of 23 hypotheses were formulated, along the lines of: "The average route speed of car traffic differs between STAR and SCOOT," or: "The delays estimated by SCOOT for car traffic match the measured delays."

In testing the zero-hypothesis (i.e. the opposite of the hypothesis), the level of significance selected for rejecting is important. We opted for a significance level of 5 per cent. In the calculations, we took account of the nature of the distribution (e.g. are the values normally distributed or not?), the division into category fields (e.g. monitoring day, monitoring period) and the number of dependent variables. We made use of the T-test, the ANOVA test, the Mann-Whitney test and the KruskallWallis test.

\section{Functioning of SCOOT}

The SCOOT system varies the length of time the lights stay green in each cycle (split), the length of the cycle 


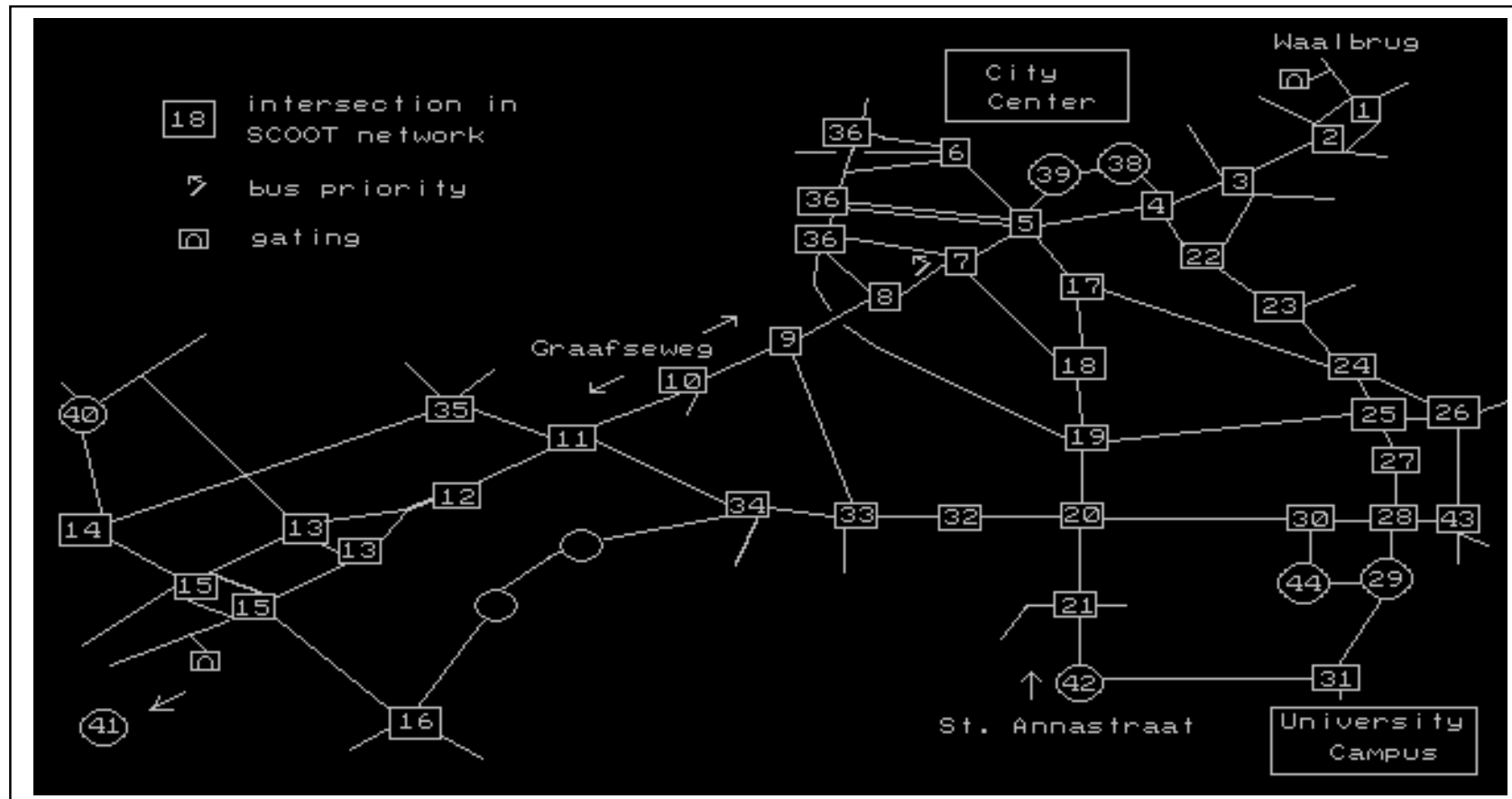

Figure 1: The SCOOT network in Nijmegen

(cycle time) and the difference between the change to green at successive junctions (offset). Upon examination, it was found that both the split and offset could be optimised without any restrictions. Only at the Keizer Karelplein (junction 5) was SCOOT unable to optimise the offset in view of the complex relationship between the traffic flows at this intersection.

The freedom to optimise the cycle time was also limited as 88 seconds is the maximum permitted value in connection with waiting times for slow traffic. As a result, there was little variation in the cycle time in the most important region, i.e. Oranjesingel (junctions 1 to 4), Graafseweg (junctions 7 - 12) and St. Annastraat (junctions 17 - 21). In the Heyendaalseweg region (junctions 22 - 28), the cycle time did, however, vary fully, namely between 36 and 72 seconds.

In the optimisation process, SCOOT makes an estimate of the delay. The extent to which these estimates correspond with the delay actually measured was examined. It was found that the estimates for the Oranjesingel (outbound) and the St. Annastraat did not tally, while those for the Graafseweg did. The differences seem to be systematic, which points to calibration defects. Since the delay, which is not calibrated directly, forms part of the optimisation process, this must affect the results.

So, the situation on which the assessment was to be based (a well-calibrated and adjusted SCOOT system) was not completely achieved. One route (Oranjesingel outbound) proved to have an unfavourable effect, since SCOOT wrongly estimated the delay.

\section{ASSESSMENT RESULTS}

For private car traffic, hypotheses were drawn up concerning journey time, route speed, delay, stops, queue length, and number of vehicles. Each of the hypotheses was tested per period, per route or junction and for the network as a whole.

\section{Private cars on different routes}

Six types of route were distinguished, namely into the city, out of the city, Keizer Karelplein, from and to the university, and transverse directions. The assessment of the hypotheses for journey time reveals that in the morning (with SCOOT) the situation improves on 4 routes, worsens on 6 routes, and 12 routes show no significant difference. In the afternoon, the situation improves on 6 routes, worsens on 7 , and 9 routes show no significant difference. In the evening, the situation improves on 1 route, worsens on 7 routes, and 14 routes show no significant difference.

The same qualitative picture emerges with the examined route speeds and delays though here and there the significance varies. The quantitative results are shown in table 1 (average delay in the network over all routes). An asterisk (*) indicates a significant difference. The effect of the deficient calibration of the Oranjesingel is also shown.

The number of stops per cycle was measured at 9 junctions. At the same time, the number of secondary stops was also examined, since these indicate the degree of network oversaturation. The analysis reveals the following qualitative picture. In the morning there are 4 
TABLE 2: Average delay in seconds

all routes

without Oranjesingel outbound

\begin{tabular}{lllllll} 
& FIXED & SCOOT & difference & FIXED & SCOOT & difference \\
\hline morning & 78 & 79 & $1 \%$ & 81 & 75 & $-7 \%\left(^{*}\right)$ \\
afternoon & 50 & 54 & $8 \%$ & 52 & 55 & $6 \%$ \\
evening & 82 & 94 & $15 \%(*)$ & 80 & 85 & $6 \%(*)$ \\
\hline
\end{tabular}

TABLE 2: Average number of stops

\begin{tabular}{lllllcc} 
& \multicolumn{2}{c}{ all routes } & \multicolumn{4}{c}{ without Waal bridge } \\
& FIXED & SCOOT & difference & FIXED & SCOOT & difference \\
\hline morning & 33 & 47 & $44 \%(*)$ & 15 & 13 & $-16 \%(*)$ \\
afternoon & 7 & 11 & $44 \%(*)$ & 6 & 9 & $44 \%(*)$ \\
evening & 15 & 28 & $89 \%(*)$ & 11 & 12 & $8 \%(*)$ \\
\hline
\end{tabular}

junctions with significantly fewer stops, 4 junctions with significantly more stops, and 1 with no significant difference. In the afternoon, we find 1 fewer, 5 more and 3 no difference. Finally, in the evening, the figures are 1 fewer, 3 more and 5 no difference.

For the quantitative analysis, a distinction must be made for the figures with and without the Waal bridge. This is because during SCOOT, gating leads to far more stops for the Waal bridge than during STAR. The differences are shown in table 2 . In terms of the number of secundary stops, SCOOT does much better. However, gating leads to far more secondary stops for traffic approaching the Waal bridge. This is shown in table 3. In absolute terms, the numbers are small, but the differences are relatively large and significant.

The queue length was calculated from the measured number of stops and the number of lanes. There is therefore a direct connection between stops and queue length. For this reason, we will not give the results for queue length.

So, the observed effects of the SCOOT system on the flow of traffic vary. On balance, SCOOT produces a better flow in the morning and STAR in the evening.

\section{Private cars in the network}

If we take a more detailed look at the flow of car traffic in the network, we see that there are hardly any significant differences at three junctions. The nonsignificant differences show a trend which indicates that more vehicles are processed during SCOOT. Summed data show that both in the morning and in the evening significantly ( 5 to 7 per cent) more traffic is processed by
SCOOT. This result cannot apparently be explained by the earlier comparison on the periphery of the network. It may, however, involve internal effects on the Nijmegen traffic network.

So, SCOOT produces a slightly better utilisation of existing network capacity in the morning and evening.

\section{Gating}

An important option offered by SCOOT version 4.2 is the "gating" mechanism. Depending on the capacity utilisation indicated by detectors in the network, the algorithm incorporated into the mechanism tries to admit as much traffic as possible without the network becoming oversaturated. In Nijmegen a gating mechanism has also been incorporated in the existing system, so that a comparison can be made between the two systems on this point too.

In general, it can be concluded that gating at the Graafseweg does not lead to a significant difference in the amount of traffic processed, the queue length or the period during which gating operates. The gating mechanism is found to be active only $25 \%$ of the time.

At the Waal bridge the situation is different. SCOOT admits significantly less traffic to the network, with the result that the queues at the Waal bridge are significantly longer and the queues in the network, at the Oranjesingel/St. Canisiussingel, significantly shorter. The gating mechanism is active nearly $100 \%$ of the time. It can readily be seen that queue length is very sensitive to small changes in the amount of traffic processed around the capacity of a junction; in the morning the queue length doubles to 3 kilometres, and in the evening it even 


\begin{tabular}{|c|c|c|c|c|c|c|}
\hline \multicolumn{3}{|c|}{ all routes } & \multicolumn{4}{|c|}{ without Waal bridge } \\
\hline & FIXED & SCOOT & difference & FIXED & SCOOT & difference \\
\hline morning & 9.0 & 13.0 & $44 \%(*)$ & 3.0 & 1.3 & $-57 \%(*)$ \\
\hline afternoon & 0.4 & 0.5 & $25 \%(*)$ & 0.3 & 0.2 & $-33 \%(*)$ \\
\hline evening & 3.4 & 5.9 & $74 \%(*)$ & 1.3 & 0.7 & $-46 \%(*)$ \\
\hline
\end{tabular}

TABLE 4: Average travel time in seconds for bicycles on Heyendaalseweg

\begin{tabular}{|ccccccccccrrrr}
\hline & \multicolumn{3}{c}{ morning } & \multicolumn{4}{c}{ afternoon } & \multicolumn{3}{c}{ evening } & \multicolumn{3}{c}{ night } \\
& Fxd & Sct & dif & Fxd & Sct & dif & Fxd & Sct & dif & Fxd & Sct & di \\
\hline north-south & 558 & 566 & $1 \%$ & 565 & 638 & $13 \%\left(^{*}\right)$ & 570 & 630 & $11 \%$ & 575 & 515 & -1 \\
south-north & 541 & 544 & $1 \%$ & 554 & 594 & $7 \%$ & 553 & 595 & $8 \%$ & 521 & 567 & 5 \\
\hline
\end{tabular}

quadruples to 1.5 kilometres.

So, the SCOOT gating mechanism is stricter than the existing gating mechanism, resulting in longer queues at one of the two gating points, but also in the elimination of network oversaturation.

\section{Public transport on different routes}

The journey times and delays on ten routes were determined during the different periods with the help of licence number observations. In qualitative terms, 4 routes show an improvement over the course of a day, 8 routes show a deterioration, 10 routes show no significant change, and for 8 there are too few observations. In quantitative terms, SCOOT shows a significantly shorter delay in the morning, mainly owing to the reduction in journey time on the Stationsplein Heyendaalseweg route from 932 to 702 seconds.

It is also interesting that, with SCOOT, the deviation in journey time (important for regular services) is considerably smaller on 7 routes, larger on 2 routes, 15 routes show no significant difference, and for 6 there are too few observations. Here, too, there is a decrease in deviation on the Stationsplein - Heijendaalseweg route from 526 to 146 seconds.

Special attention was devoted to public transport on the Graafseweg to railway station route via Van Oldenbarneveltstraat. At this junction, STAR modified the priority. It was found that this modification reduces the average delay and deviation. After the assessment, the priority at this junction was also altered within SCOOT.
So, the SCOOT system guarantees the flow of public transport but bus priority requires further attention.

\section{Cyclists and pedestrians}

The effects of SCOOT on cyclists and pedestrians were measured by observers following other cyclists on the route from the centre to the university and back via Heyendaalseweg. In only 12 of the 24 cases are there any differences. Where the difference is significant, SCOOT generally comes out worse. Most of the differences can be explained by the longer cycle times achieved by SCOOT in this region. The results for the whole northsouth and south-north route are shown in table 4. Only in one case is there a significant difference.

In addition to the effect of SCOOT on cyclists who travel with a main flow, another is the degree to which the ease of crossing main routes is altered for slow traffic. This is determined by cycle time and split. During three monitoring periods 10 situations were examined. In 15 cases, the average waiting time was shorter with SCOOT and in the other 15 cases it was shorter with STAR. The differences are small, amounting to just a few seconds. On the Heyendaalseweg, the effect is greater; the average waiting time falls from 25 to about 15 seconds during all periods.

So, the effects of SCOOT on slow traffic vary.

\section{SUMMARY}

SCOOT's effect on traffic is no better or worse than the existing fixedtime coordinated control system. Expectations were, however, somewhat higher, mainly 


\begin{tabular}{llllll}
\multicolumn{2}{l}{ TABLE 5: } & Some figures from 4 major cities and Nijmegen & & & \\
& Amsterdam & Rotterdam & The Hague & Utrecht & Nijmegen \\
\hline inhabitants & 700.000 & 600.000 & 480.000 & 240.000 & 150.000 \\
controlled junctions & 300 & 217 & 245 & 135 & 120 \\
vehicle actuated & $160(53 \%)$ & $217(100 \%)$ & $230(94 \%)$ & $115(85 \%)$ & $30(25 \%)$ \\
fixed time & $140(47 \%)$ & $0(0 \%)$ & $15(6 \%)$ & $20(15 \%)$ & $90(75 \%)$ \\
public transport priority & $100(33 \%)$ & $130(60 \%)$ & $185(76 \%)$ & $80(59 \%)$ & $15(13 \%)$ \\
coordinations & $100(33 \%)$ & $40(18 \%)$ & $120(49 \%)$ & $65(48 \%)$ & $90(75 \%)$ \\
\hline
\end{tabular}

due to other assessments showing that SCOOT worked much better than the old control systems. The causes of these lesser results probably are the fact that Nijmegen has an active policy in control, so existing control programs are never 'aged'. Other causes are the specific infrastructure (Keizer Karelplein, the pivot of the traffic network) and the fact that SCOOT was not given full freedom since the maximum cycle time at the Keizer Karelplein is 88 seconds.

The system in Nijmegen does remain operational, as it's planned to do an extra validation and assessment in the course of 1996. Apart from this it's expected that major changes in traffic policy, with respect to public transport, will show an emphasize on the construction of buslanes, to bypass queues, and on priority in traffic control.

\section{SITUATION IN THE NETHERLANDS}

The results in Nijmegen mean that there is no compelling reason to carry out a new trial elsewhere in the near future in The Netherlands. The results cannot be generalised as the situation in Nijmegen differs too much from the four major cities. See for instance the difference in the figures in table 5, which can be explained historically.

In the early 70s, the introduction of minicomputers provided more scope for programming the systems and enabled vehicle-related programs to be developed. This period saw the emergence of designing traffic control systems for individual junctions, with priority for public transport. The late 1970s saw the rise of microcomputers, with the introduction of the micro-processor in junction control systems. At this stage the intelligence shifted from the central system to the junction.

The greatest step forward in the Netherlands in recent years has been the introduction of a $\mathrm{C}$-interface in traffic control devices. This has created an interface between road authorities and manufacturers, and among different manufacturers, and has led to a certain amount of "openness" in the systems.

\section{FUTURE}

The assessment of SCOOT in Nijmegen confirms what Gartner reported in 1994 in the framework of the IVHS congress "Towards an Intelligent Transport System" (4): second- and third-generation control systems, produce an improvement in some instances and a deterioration in others. Gartner concluded that work should be carried out on new generations of control systems with a more hierarchical intelligence.

Developments with the SCOOT system are directed towards giving priority to public transport, integrating other traffic measures such as route guidance and incident management, and making the on-line data more accessible. However, as long as the technology continues to be based on stages, this will severely limit what can be achieved.

Developments in the Netherlands are stagnating due to the lack of a standard communication protocol for traffic networks in cities. If traffic control in cities is to develop towards more hierarchical and functional systems, the road authorities will have to standardise communication between central and local systems. The experience with SCOOT in Nijmegen may prove very useful in this respect. European developments should preferably be taken into account.

\section{REFERENCES}

1. Middelham F, Dibbits J and Fransen W, 1994, "The implementation of SCOOT in Nijmegen", proceedings RTMC-congres, 125-130

2. Taale H, 1992, "Evaluatieplan SCOOT-inNijmegen", Rijkswaterstaat AVV, Rotterdam

3. Witteveen+Bos, 1994, "Evaluatie SCOOT in Nijmegen", Rijkswaterstaat AVV, Rotterdam

4 Gartner N, Stamatiadis C, Tarnoff P, 1994, "Development of Real Time Traffic-Adaptive Control Strategies", IVHS-congress, Paris, Volume $2,423-430$ 
